\title{
DON DIEGO DE ARAGÓN, IV DUQUE DE TERRANOVA, Y EL ENVÍO DE ESCULTURAS PARA FELIPE IV DURANTE SU EMBAJADA EN ROMA
} (1654-1657)

La circulación de obras de arte por las vías de la diplomacia durante la Edad Moderna se ha desvelado como uno de los factores decisivos a la hora de configurar ciertas colecciones de primer orden en el contexto europeo, como sin duda lo fue la de los reyes de España en el siglo XVII. La fuerte presencia española en el panorama político de Italia durante aquel siglo y la alta cualificación de los artistas italianos determinó que la vecina península fuera el lugar donde fueron realizadas buena parte de las obras que vinieron a España por esas vías.

Un reciente hallazgo documental permite ahora aclarar uno de los episodios más singulares que tuvieron lugar durante el reinado de Felipe IV, el encargo de esculturas en Roma por parte de su embajador ante la Santa Sede entre 1654 y 1657, don Diego de Aragón, IV duque de Terranova. La conservación en el Archivo General de Simancas de las cuentas emanadas de la gestión de la embajada durante el tiempo en que Terranova fue su máximo responsable, permite aclarar con exactitud cuáles fueron los encargos artísticos que el embajador hizo durante aquellos años por orden de Felipe IV, entre los que se encontraba, como se había supuesto pero no demostrado hasta el momento, el famoso Cristo de bronce de Gian Lorenzo Bernini, conservado en El Escorial. Además, Terranova gestionó, al menos en parte, el encargo, fundición y traslado a España de los conocidos morillos de Alessandro Algardi, así como mandó realizar diversos bufetes de pórfido para algunas estancias del Alcázar, para donde también compró y expidió una serie de los Doce Emperadores, labrada igualmente en pórfido.

Asociados al deseo de renovar la decoración interior del Alcázar de Madrid, y en consecuencia a la bien conocida misión de Velázquez durante su segundo viaje a Italia, los encargos de Terranova a artistas establecidos en Roma vinieron a completar el plan regio destinado a dotar el Alcázar de unas salas de representación adecuadas al lugar que España ocupaba entre las naciones del viejo continente.

Terranova, miembro de una aristocrática familia de origen siciliano, fue embajador de España en Roma desde febrero de 1654 hasta junio de 1657. Con anterioridad, había servido al mismo Felipe IV en un análogo cargo diplomático en Alemania ${ }^{1}$. Desde Italia, el duque había colaborado en 1649, según publicó Justi en su pionero estudio sobre Velázquez, en el traslado del escultor Giuliano Finelli de Carrara a Roma para que realizase las copias de esculturas antiguas y las obras de nueva factura que el pintor sevillano estimase oportunas ${ }^{2}$. Ya como embajador en Roma, continuó los trabajos de remodelación del palacio de España, comenzados años atrás por el conde de Oñate, si bien las obras dejaron entonces de ser dirigidas por Francesco Borromini para estar a cargo de Antonio del Grande, arquitecto vinculado con el hispanófilo cardenal Girolamo Colonna ${ }^{3}$. También promovió algunas celebraciones públicas notables, como por ejemplo la que tuvo lugar en el verano de 1654 con motivo de su entrega del tributo de la chinea al Papa ${ }^{4}$.

La principal obra encargada por Terranova durante su embajada en Roma fue el Cristo crucificado de Gian Lorenzo Bernini (Fig. 1), cuyo primer destino fue el altar del Panteón Real del monasterio de El Escorial. No había sin embargo hasta el momento evidencia documental sobre el encargo a Bernini de la escultura, por lo que permanecía la duda de si el Cristo llegó

\footnotetext{
${ }^{1}$ Sobre la familia Terranova, véase Aymard, M.: «Une famille de l'aristocratie sicilienne aux XVIe et XVIIe siècles: les ducs de Terranova», Revue Historique, 247, 1972, pp. 29-65.

${ }^{2}$ Justi, K.: Velázquez y su siglo, Madrid, 1953, p. 562.

${ }^{3}$ Anselmi, A.: Il Palazzo dell'Ambasciata di Spagna presso la Santa Sede, Roma, 2001, pp. 77-104.

${ }^{4}$ Ibídem, p. 205.
} 
a la regia fundación como regalo del Sumo Pontífice, como defendía un estudioso del artista, o tras haberle sido comisionado por orden del mismo Felipe IV. Las fuentes impresas se inclinan sin duda por la segunda opción; Baldinucci afirmaba que Bernini «condusse ad instanza del Re delle Spagne Filippo IV il gran Crocifisso di bronzo, che ebbe luogo nella Cappella de'Sepolcri de'Re» ${ }^{5}$. Sin embargo, una nota publicada por Stanislao Fraschetti en su monografía de Bernini de 1900, recogida por Tormo en su estudio sobre los crucifijos de El Escorial, apuntaba otra vía para la llegada de la obra a España. Según la documentación aportada por Fraschetti, el Cristo había sido regalado por Inocencio X a la reina Mariana cuando la esposa de Felipe IV se encontraba en Milán camino de España. Sin embargo, en tal documento no se menciona en ningún momento que el presente fuese de mano de Bernini ${ }^{6}$.

La documentación de Simancas viene a despejar definitivamente esta incógnita, pues en ella queda explícito que Terranova pagó a Bernini a cuenta del Cristo de bronce que el rey había ordenado se hiciese. Además, se recoge que una vez que estuvo terminado, se embaló y se llevó en carro hasta el puerto de Civitavecchia, y allí se embarcó con rumbo a Alicante, desde donde se mandó a Madrid. Por el diario del cardenal Fabio Chigi, futuro Alessandro VII, se sabe que el Cristo estaba acabado el 8 de febrero de 1654, cuando el prelado pudo verlo y discutir con el duque de Terranova algunos particulares de su envío a España ${ }^{7}$. Por tanto, si la obra estaba concluida en los primeros meses de 1654, la gestión de la misma tuvo que hacerse con anterioridad a que Terranova fuese nombrado embajador, lo cual no excluye que fuese el mismo noble quien hubiese realizado el encargo a Bernini. Así, el pago registrado en el documento de Simancas no sería el importe total del Cristo, sino más bien un último plazo de lo acordado.

La obra llegó a España en 1654, siendo descrita tres años después por Francisco de los Santos ya en el lugar para el que se había encargado, el altar del Panteón Real del monasterio de El Escorial ${ }^{8}$. El rey debió quedar satisfecho con el trabajo de Bernini, pues al parecer, como algunos biógrafos afirman, le recompensó con un collar de oro ${ }^{9}$.

Pero como es bien conocido, el Cristo no permaneció mucho tiempo en aquel lugar. Fuese por ser su tamaño demasiado pequeño, o por considerarse demasiado bello para estar tan apartado de la contemplación habitual, lo cierto es que se contrató en Roma la realización de un nuevo Crucificado con Domenico Guidi para reemplazar el de Bernini. El Cristo de Guidi llegó a España en julio de 1659 , siendo remitido al rey por trámite de Terranova ${ }^{10}$, quien por entonces ya no estaba en Italia, sino que se encontraba en Madrid, ocupando el cargo de su-

\footnotetext{
${ }^{5}$ Baldinucci, G.: Vita del Cavalier Bernino, Florencia, 1682, p. 37. En la página 74, afirma el mismo autor que «aveva il cavaliere fatto per la Maestá del Rè di Spagna il crocifisso di bronzo».

${ }^{6}$ Fraschetti basa su hipótesis en un fragmento del diario Cigli relativo al año 1649, en el que se dice: «Papa Innocentio mandó il Cardinale Ludovisio suo parente, legato de latere a Milano a fari i complimenti con Maria Anna d'Austria figlia di Ferdinando Imperatore, nova sposa di Filippo 4, Re di Spagna che era giunta in Milano, et a di 4 agosto il $\mathrm{d}^{\circ}$ Cardinale fece l'offitio, et donó alla Regina da parte del Papa un Corpo Santo dentro una richissima cassa, et quattro bauli, doi pieni di medaglie d'oro e d'argento et doni pieni di Agnus dei, et la Rosa d'oro benedetta». Citado por Tormo, E.: «Los cuatro grandes crucifijos de bronce dorado de El Escorial. Obra de Pompeo Leoni, Pietro Tacca, Lorenzo Bernini y Domenico Guidi», en Pintura, escultura y arquitectura en España. Estudios dispersos, Madrid, 1949, pp. 355-379; la cita, en p. 374.

${ }^{7}$ Lo recuerda Rodriguez Ruiz, D.: «Sobre el modelo de bronce de la Fontana dei Quattro Fiumi de Guan Lorenzo Bernini conservada en el Palacio Real de Madrid», Reales Sitios, 155, 2003, pp. 26-41, en particular en pp. 31-33. La nota del diario de Chigi la publica Petrucci, F.: «Algardi, Cortona ed altri artisti nel diario di Fabio Chigi Cardinale (1652-1655)», Rivista dell'Istituto Nazionale di Archeologia e Storia dell'Arte, 21, 1998, pp. 169-196.

${ }^{8}$ Wittkower, R.: Gian Lorenzo Bernini. El escultor del barroco romano, Madrid, 1990, pp. 264-265. Véase también Martín González, J.J.: El escultor en Palacio. Viaje a través de la escultura de los Austrias, Madrid, 1991, pp. $193-197$.

9 Fagiolo dell'arco, M.: L'imagine al potere. Vita di Gianlorenzo Bernini, Roma-Bari, 2001, p. 290, afirma la posesión de Bernini de un collar de oro regalado por Felipe IV en recompensa por el Crucificado de El Escorial.

${ }^{10}$ A.G.S., Cámara de Castilla, Cédulas, 369, fol. 298r, 28 de julio de 1659: «El Rey (...) Por orden del marqués (sic) de Terranova se me remite una caxa en viene un Santo xto». Publicado en Morán Turina, M. y Rudolf, K.: «Nuevos documentos en torno a Velázquez y las colecciones reales», Archivo Español de Arte, 65, 1992, p. 301.
}

AEA, LXXVIII, 2005, 311, pp. 297 a 331 

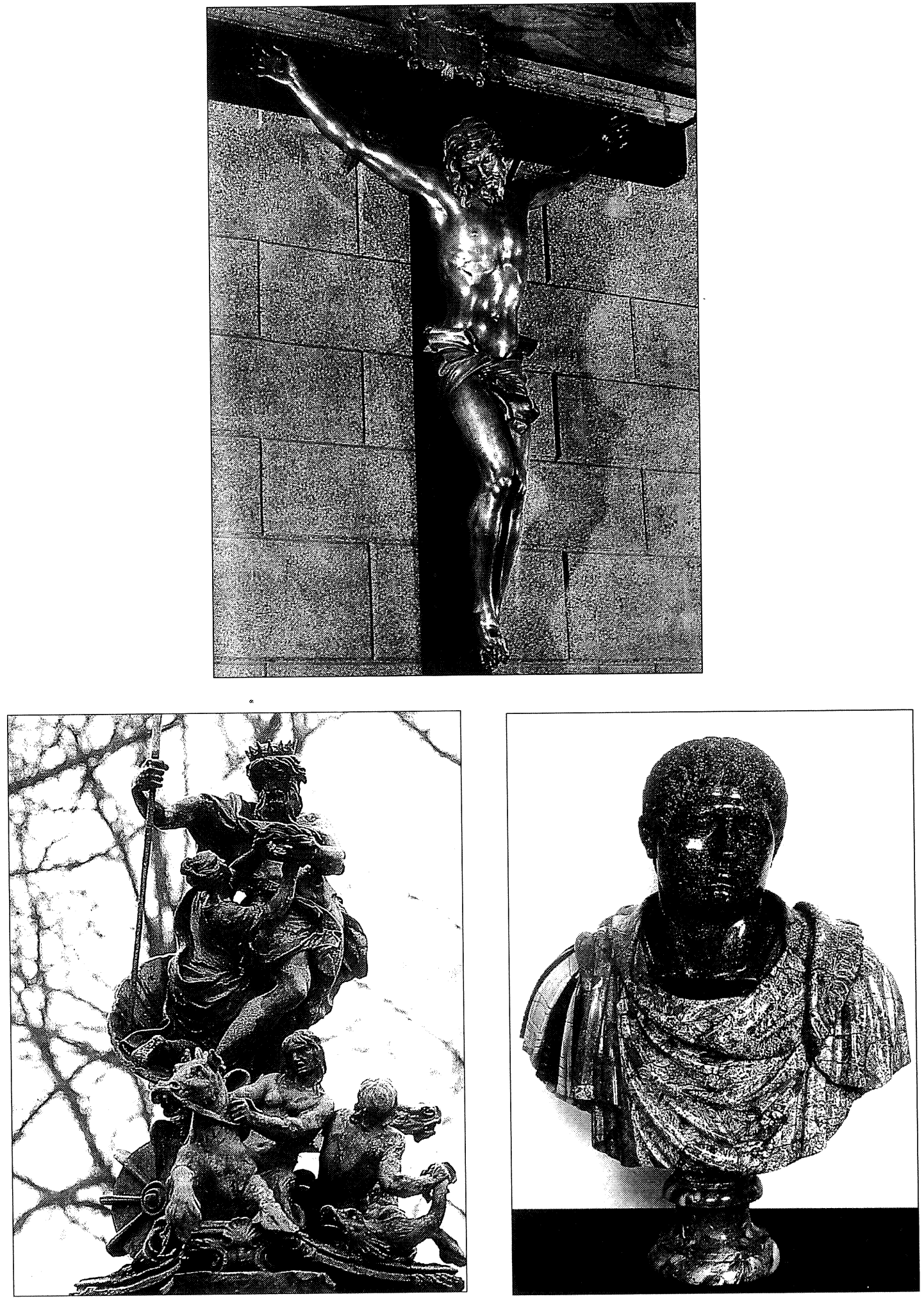

Fig. 1. G. L. Bernini. Cristo Crucificado. Monasterio de El Escorial.

Fig. 2. A. Algardi. Neptuno. Aranjuez, Jardín de la Isla.

Fig. 3. Anónimo. Otón. Madrid, Palacio Real.

AEA, LXXVIII, 2005, 311, pp. 297 a 331 
perintendente de las obras reales ${ }^{11}$. Sin embargo, Palomino afirma que el nuevo Cristo lo mandó hacer en Roma el mismo Terranova ${ }^{12}$, por lo que, de estar en lo cierto el historiógrafo, el encargo debió hacerlo antes de su vuelta a España, pero después de cesar como embajador, pues no hay partida alguna en sus cuentas con tal destino.

Una vez hubo llegado a El Escorial el de Guidi, el Cristo de Bernini se instaló definitivamente en la capilla del Colegio del Real Monasterio, donde el arquitecto y ensamblador José de la Torre realizó un retablo para albergarlo, según una traza elegida por el mismo Felipe IV ${ }^{13}$.

En la memoria de los gastos de la embajada, Terranova también se atribuye haber encargado para el rey unos bufetes de pórfido y unos morillos de bronce, que debieron probablemente ser aquellos que realizó Alessandro Algardi. Durante su segunda estancia italiana, en 1650, Velázquez encargó a Algardi la realización de una serie de cuatro parejas de morillos destinados al Alcázar de Madrid, los cuáles debían representar a los dioses Neptuno (Fig. 2), Cibeles, Juno y Júpiter, en alusión a los cuatro elementos ${ }^{14}$, vaciándose dos ejemplares idénticos de cada grupo. En 1654, Algardi estaba trabajando en los modelos en terracota, siendo aquel mismo año enviados a España los grupos de Júpiter y Juno, si bien no llegaron nunca a causa del naufragio de la nave que los transportaba. Así debieron hacerse de nuevo, encargándose del fundido de éstos y de los de Neptuno y Cibeles Domenico Guidi y Ercole Ferrata ${ }^{15}$.

El 19 de enero de 1654, los morillos fueron enviados por el Tíber al puerto de Civitavecchia, para que allí monseñor Camillo Massimi los cargase en la galera que debía conducirle a España, donde se dirigía para hacerse cargo de la nunciatura de Madrid, pero por la agitación del mar, no pudieron llegar a tiempo de ser embarcados. Decía Massimi de ellos en una carta enviada a Velázquez al respecto: «Sono veramente riusciti bellissimi, e molte volte io sono stato dal Cav[alie]re Algardi à vederli» ${ }^{16}$.

${ }^{11}$ En 1658, Terranova ocupaba el cargo de superintendente de las obras reales, como manifiesta Palomino con ocasión de la llegada a Madrid de los pintores boloñeses Agostino Mitelli y Angelo Michele Colonna. Véase Palomino, A.: Vidas, Madrid, 1988, p. 252: «Llegaron [Mitelli y Colonna] a Madrid el año de 1658, donde fueron muy agasajados, y asistidos de Don Diego Velázquez: aposentóles en la Casa del Tesoro, en un cuarto principal, y a su cargo estuvieron las pagas, que cada mes se les hacían; en cuya disposición y concierto intervino también el Duque de Terranova, como Superintendente de las obras reales».

12 «El año de 1659, llegó a España la Imagen del Christo Crucificado de bronce, y dorado, que mandó hazer en Roma de orden del.Rey el Duque de Terranova, para la Capilla Real del Pantheon, entierro de los Catholicos Monarchas de España. Fue su artífice un sobrino de Julián Fineli, que siendo mozo, mostró en esta obra más de lo que se esperaba. Trajéronlo a Palacio por el mes de noviembre, y fue visto de su Magestad en la Pieza Ochavada, y luego mandó a Diego Velázquez diese orden de llevarlo a San Lorenzo el Real, y que fuese también allá, para ver la forma que se avia de tener en su colocación; hízolo como su Magestad lo mandaba». Palomino no precisa quién era el autor; en realidad, el segundo crucificado es obra de Domenico Guidi, sobrino de Finelli. Véase Tormo, E.: Ob. cit., pp. 366-369.

${ }^{13}$ A.G.S., Contaduría Mayor de Cuentas, $3^{a}$ época, 2995, n 2, fascículo 71. Pagos de Francisco de Arce, Alcázar de Madrid, 1657-1660: «A Joseph de la Torre architecto y ensamblador vezino desta villa dos mill y quatrocientos reales que valen ochenta y un mill y seiscientos maravedís por quenta de quatro mill y seiscientos reales en que se concertó con él hacer el retablo y adorno para el santo Xpto de bronce que se a de poner en la Capilla del Colexio del Conbento Real de san Lorenço en el Escurial comforme a la traza que elijio Su Mag.d». Esta circunstancia es recogida por el padre De los Santos, quien afirma en las ediciones de 1681 y 1698 de su Descripción: «estuvo [el Cristo de Bernini] antes en la capilla del Panteón, y por ser pequeño para allí, aunque tiene cinco pies de alto, mandó el Católico Rey Felipe Quarto se pusiera aquí [en la Capilla del Colegio] y se le hiciesse este retablo, para que estuviese con decencia". Cita tomada de Tormo, E.: Ob. cit., p. 361 .

${ }^{14}$ Bellori, G.P.: Le vite de Pittori, Scultori ed Architetti moderni, Roma, 1672, p. 401: «In ultimo per servigio del Re di Spagna Filippo IV fece li capofocolari, quando l'anno 1650, venne a Roma Diego di Velasco eccellentissimo pittore di ritratti. Queste fece formare e gettare di bronzo alcune statue antiche (...) ma li capofocolari furono quattro e rappresentano li quattro Elementi (...)».

${ }^{15}$ Martín González, J.J.: Ob. cit., pp. 187-188. Mariana de Austria los destinó a una de las fuentes del Jardín de la Isla de Aranjuez, donde hoy se conservan tres de ellos, uno de Neptuno y los dos de Cibeles, habiendo desaparecido todos los demás:

${ }^{16}$ Colomer, J.L. y Harris, E.: «Two letters from Velázquez to Camillo Massimi», Burlington Magazine, 136, 1994, pp. 545-548. Las carta, en copia, se conserva en el Archivio Massimi de Roma, Prot. 275, pp 19-20.

AEA, LXXVIII, 2005, 311, pp. 297 a 331 
El envío o bien se vio considerablemente retrasado o se fragmentó en varias partidas, pues hasta el año siguiente no hay noticia de su llegada a España. Hacia el 22 de noviembre de 1655, arrivaron a los puertos de Cartagena y Alicante veinte tercios que contenían «algunos bufetes de Porfido con sus pies de madera, y unos morillos de bronce dorado para adorno de mi Palacio Real» que, según la cédula real expedida para la exención del pago de impuestos de aduanas, habían sido encargados en Roma por el conde de Oñate ${ }^{17}$.

Esta última afirmación no deja de ser problemática. Dado que Oñate había sido embajador desde julio de 1646 a febrero de 1648, sorprende que el encargo hubiese tardado tantos años en ser concluido y enviado. Además, de haber sido este noble quien comisionó las obras, habría que descartar que el contacto con Algardi tuviese lugar por mano de Velázquez en 1650. Puede también que el lote de bufetes y morillos referido por la cédula fuese uno distinto al que contenía los de Algardi, o puede que la mención de Oñate naciese del recuerdo confuso de Felipe IV. En cualquier caso, los pagos de Simancas recogen que Terranova encargó, pagó y envió desde Civitavecchia hasta Alicante, con una parada en Génova, unos morillos de bronce, así como compró unos pórfidos con los que se hicieron diversos bufetes, algunos de los cuáles iban «guarneçidos con franxas de cobre dorado». En los inventario del Cuarto del Rey del Alcázar realizado por la testamentaría de Carlos II, figuran una serie de seis bufetes con estas características ${ }^{18}$, que no son otros que los que amueblaban el Salón de los Espejos, aquellos que estaban sostenidos por las parejas de leones de bronce encargados por Velázquez en $1650 \mathrm{y}$ fundidos por Matteo Bonarelli ${ }^{19}$.

Terranova también gastó caudales «en comprar unas caveças de emperadores de la misma piedra [pórfido]». Al igual que las otras obras, la serie de emperadores fue enviada de Roma a Civitavecchia, donde la embarcaron junto con los bufetes hacia Barcelona. Una vez en el puerto catalán, fueron «perfumadas» y guardadas en nuevas cajas, y de allí salieron en carro hacia Madrid, si bien éste fue detenido en Zaragoza hasta que llegó la oportuna orden de Felipe IV para su entrada en Castilla libre de impuestos.

De las series de bustos de los Doce Emperdores de Roma vinculadas con las colecciones reales españolas, estudiadas por Stephan Schröder, se conserva parte de una que probablemente puede identificarse con la comprada y enviada por Terranova. Se trata de la del Salón de Columnas del Palacio Real de Madrid, que además de ser la única en la que se emplea en las cabezas el material citado en las cuentas -el pórfido-, entró en las regias colecciones en un momento desconocido hasta ahora ${ }^{20}$. De los doce bustos, sólo se conservan tres completos, los de Julio César, Augusto y Otón (Fig. 3), quedando las cuatro cabezas de pórfido de otros tantos bustos ${ }^{21}$.

La actividad de Terranova en pro del enriquecimiento de las colecciones de escultura de Felipe IV no se limitó a las adquisiciones y gestiones hasta ahora recordadas; también consta que durante su embajada, el 10 de marzo de 1657, envió a Madrid una carta con la que preten-

\footnotetext{
${ }^{17}$ Morán, M. y Rudolf, K.: Ob. cit., p. 294. La carta se conserva en AHN, Consejos, Libro 2426, fol. 2-3.

18 «Primeramente Seis Bufettes de porfido Yguales de Siette pies de largo por tres Y medio de ancho Cada Uno Con molduras de Bronce dorado, y Cada Bufette tiene por pies dos leones al natural de Bronze dorado Con Una Bola de marmol Sobre que descansa una mano de Una mano de cada leon». Veáse Fernández Bayton, G.: Inventarios reales I. Testamentaría del rey Carlos II, 1701-1703, Madrid, Museo del Prado, 1975, I, p. 129.

${ }^{19}$ Salort Pons, S., Velázquez en Italia, Madrid, 2002, p. 103, aclara que los doce leones fueron enviados a España en dos remesas, una a finales de marzo de 1651 y otra a finales de abril del año siguiente.

${ }^{20}$ Schröder, S.: «Las series de los Doce Emperadores», en El coleccionismo de escultura clásica en España. Actas del simposio, Madrid, Museo del Prado, 2001, pp. 43-60, en especial pp. 54-55. Según este autor, dos de las «cavezas de pórfido» aparecen por primera vez en el inventario de la testamentaría Carlos II de 1703, año en que se encontraban en la galería de Retratos del Alcázar.

${ }^{21}$ Ibídem, pp. 56-57, reproduce estos bustos y cabezas. Sorprende que entre las cuatro cabezas, se encuentre otro personaje identificado con Augusto, siendo las otras de Nerón, Claudio y Vespasiano.
} 
día advertir a Felipe IV de la posibilidad de adquirir en Roma una serie de importantes esculturas, las cuales eran conocidas por Velázquez ${ }^{22}$.

Aquel mismo año, la superintendencia de las obras reales en Madrid era dirigida por el marqués de Malpica, quien contaba con la asistencia de Diego Velázquez ${ }^{23}$. Sin embargo, poco después, el universal pintor vio cómo Terranova se convertía en el nuevo superintendente de las obras de Felipe IV, quedando así el aristócrata seguramente recompensado por su eficaz dedicación al enriquecimiento artístico de los Reales Sitios españoles.

DAVid García Cueto

Universidad de Granada

\section{APÉNDICE DOCUMENTAL}

A.G.S., Tribunal Mayor de Cuentas, 2634. Cuentas de don Diego de Aragón, duque de Terranova, durante su embajada en Roma, 1654-1657. Año de 1657.

«Mas di al Bernin por la obra del Santo Cristo de bronce que S.M. me mando hacer mil escudos.

Mas gaste en hacerle encaxar en flete de aduanas carruaxe asta Civitaviexa y de Alicante a Madrid ducientos y veinte y cinco escudos.

Mas di a la persona que le llevo para aiuda al gasto de la yda y buelta ducientos escudos.

Mas gaste en unos morillos de Bronce que de orden de S.M. hice hacer y remitir mil y seiscientos escudos.

Mas en acerlos encaxar carruaxe asta Civitaviexa flete asta Jenoba y de Jenoba a Alicante y de aduanas trescientos escudos.

Mas gasté en comprar unos porfidos de que se hicieron unos bufetes para S.M. y algunos dellos ban guarnecidos con franxas de cobre dorado y en comprar unas caveças de emperadores de la misma piedra en encaxar todo esto y en el carruaxe asta Civitaviexa cinco mil escudos.

Mas pagué en Barcelona para perfumarlos y bolveros a encaxar cien escudos.

Mas en carruaxe de Barcelona a Madrid haviendo pesado todo seiscientas ochenta y dos arrovas y media a quince reales de plata cada arrova diez mil y ducientos y treinta y siete reales y medio de plata

Mas pagué de la detención de dicho carruaxe en Çaragoza a donde no le quisieron dexar pasar asta tener orden de S.M. ducientos escudos».

\footnotetext{
${ }^{22}$ Pita Andrade, J.M.: «Dos recuerdos del segundo viaje a Italia», Archivo Español de Arte, 25, 1952, p. 289. Terranova vio oportuno «embiar a Ve. la inclusa memoria de estatuas y vasos de toda curiosidad» con el deseo de contribuir, caso que se comprasen, al enriquecimiento de las colecciones reales, «que tanto junto y tan bueno a dicho de los del Arte no lo ay en todo el mundo ni se puede juntar, cosa por cosa, en muchos siglos». La carta se conserva en al Archivo de la Casa de Alba, c. 182-184.

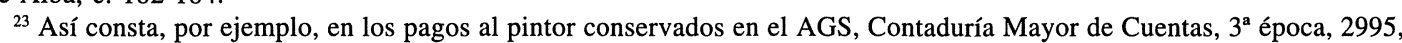
$\mathrm{n}^{\circ}$ 2, fascículo 16. Francisco de Arce, pagador del Alcázar de Madrid: «A Diego de Silva Belazquez ayuda de Camara de Su Mag.d que asiste a la superintendencia de las obras partiqulares que Su Mag.d señalare devaxo de la mano del marqués de Malpica superintendente de las obras Reales Ziento y treinta y Cinco mill maravedis que huvo de haver desde primero de Julio de mill y seiscientos y cinquenta y siete hasta fin de Diziembre dela relación, de sesenta ducados que goça de salario al mes con el dicho oficio en virtud de zedula de Su Mag.d».
}

AEA, LXXVIII, 2005, 311, pp. 297 a 331 